\title{
DARI AKSI HINGGA PESTA DEMOKRASI: DINAMIKA PARTAI RAKYAT DEMOKRATIK MENUJU PEMILU (1996-1999)
}

\author{
Oleh \\ Cahyo Susilo ${ }^{1}$
}

\begin{abstract}
This research illustrated the historical event in Indonesia, especially in 1990 s period. The study examined the development of People Democratic Party as one of the political parties in the New Order regime. This research-based on the author's interest in the pro-democracy movement's widespread in Indonesia, evidenced by the resistance movement of peoples, in this case, is the People Democratic Party. The study aimed to identify programs and strategies of the People Democratic Party to build a prodemocracy movement in the 1996-1999 period. The author used the historical method. People Democratic Party was one of the political party which develop at that time and had a political movement to subvert a New Order regime. People Democratic Party often referred to as a radical political party, because of the political program that confronted the New Order regime namely to eliminate the Indonesian National Armed Forces Dual function, to eliminate a five-pack of Political Act and Timor-Timur referendum. The impact, People Democratic Party regarded as a forbidden party and accused as the actor behind July 27th 1996 tragedy. After the tragedy, the People Democratic Party arose with people's committees. The four elements of People Democratic Party namely (1) the urban poor, (2) workers, (3) youth people, (4) PDI-Megawati supporters. After 1998 Reformation, People Democratic Party declared as a legal party and has participated as a contestant of 1999 electoral. People Democratic Party argued that the Electoral system is a moment for campaigning political programs. Several things in the campaign was about amnesty for political prisoners, completion of Civil Rights violation cases, and people's political rights.
\end{abstract}

Keywords: People Democratic Party, People’s Committees, 1999 Electoral.

${ }^{1}$ Cahyo Susilo adalah mahasiswa Departemen Pendidikan Sejarah FPIPS UPI. Penulis dapat dihubungi di alamat e-mail: cahyo.soesiog@gmail.com. 


\section{PENDAHULUAN}

Gerakan reformasi tahun 1998 adalah sebuah mosi tidak percaya kepada rezim otoriter Orde Baru. Jatuhnya Orde Baru merupakan awal mula dimulainya kehidupan yang lebih demokratis di Indonesia. Reformasi terjadi karena adanya kekuatan ekstra-parlementer yang sedikit demi sedikit merongrong kekuasaan Orde Baru. Hal tersebut dibuktikan dengan munculnya kritik dan protes terhadap kekuasaan Orde Baru menjelang keruntuhannya.

Salah satu entitas politik yang mempelopori kekuatan ekstraparlementer di Indonesia adalah Partai Rakyat Demokratik (PRD). PRD adalah sebuah organisasi massa dengan fokus membangun struktur perlawanan terhadap kekuasaan rezim Orde Baru pada pertengahan 1990-an. Dengan mengusung asas Sosial Demokrasi Kerakyatan, PRD menjadi organisasi masyarakat dengan posisi vis a vis dengan pemerintahan Soeharto.

PRD dideklarasikan sebagai partai politik pada 22 Juli 1996 dengan programprogram politik yang berkonfrontasi langsung dengan rezim Orde Baru. PRD meyakini bahwa dengan mencabut pilarpilar kekuasaan Orde Baru (seperti 5 Paket UU Politik 1985, dan Dwi Fungsi ABRI) maka kehidupan demokratis di Indonesia akan segera dirasakan. Usaha tersebut bukan tanpa hambatan, selang 5 hari setelah mendeklarasikan diri sebagai partai politik, PRD dituduh sebagai dalang aksi kerusuhan di Jl. Diponegoro Jakarta Pusat. Beberapa pimpinan partai kemudian ditangkap dan diadili, dan akhirnya PRD ditetapkan sebagai organisasi terlarang melalui SK Mendagri No.210-221 Tahun 1997.

Walaupun ditetapkan sebagai organisasi terlarang, namun PRD tetap menjalankan program-program politisnya untuk membentuk sentimen kebencian terhadap Orde Baru. Hingga pada akhirnya meletuslah aksi massa pada bulan Mei 1998 yang membawa Soeharto turun dari kekuasaannya. Pasca Soeharto turun dari tampuk kekuasaannya, pemerintahan kemudian menyelenggarakan pemilihan umum legislatif pada tahun 1999 sebagai jawaban atas tuntutan reformasi agar dilaksanakan pemilihan umum yang jujur dan adil. Uniknya, PRD sebagai partai politik ekstraparlementer memutuskan untuk ikut berpartisipasi dalam kontestasi politik tersebut.

Keikutsertaanpartaiyangberbasispada aksi-aksi massa dan demonstrasi dalam pemilihan umum legislatif merupakan keunikan tersendiri, mengingat PRD sebelumnya selalu mengkampanyekan boikot pemilu dan golput dalam pemilu. Dalam hal ini, penulis akan memfokuskan penelitian pada perkembangan Partai Rakyat Demokratik pasca kerusuhan 27 Juli 1996 dan pelarangan oleh Menteri Dalam Negeri hingga pada akhirnya PRD memutuskan untuk melanjutkan perjuangan parlementaris dalam Pemilu 1999.

\section{Metode Penelitian}

Dalam penelitian ini, penulis menggunakan metode penelitian historis atau metode sejarah. Metode historis menurut Ismaun (2005, hlm. 34) dan Sjamsuddin (2012, hlm. 10-11) ialah rekontruksi imajinatif tentang gambaran 
masa lampau peristiwa-peristiwa sejarah secara kritis dan analitis berdasarkan bukti-bukti dan data peninggalan massa lampau yang disebut dengan sumber sejarah. Berdasarkan uraian tersebut dapat disimpulkan bahwa metode sejarah merupakan teknik penelitian dalam merekonstruksi masa lampau, melalui empat tahap, yaitu heuristik (pengumpulan sumber), kritik sumber, interpretasi (penafsiran), dan historiografi (penelitian kisah sejarah) (Hamid \& Madjid, 2011b).

Adapun langkah-langkah tersebut menjadi prosedur kerja yang penulis lakukan untuk menuliskan kisah masa lampau berdasarkan bukti-bukti yang ditinggalkan. Proses pencarian jejak-jejak masa lampau atau sumber sejarah disebut heuristik, yang kemudian diseleksi untuk memastikan keaslian dan sejauh mana sumber tersebut dapat dipercaya dengan melakukan proses kritik. Berdasarkan informasi yang diperoleh kemudian penulis berusaha membayangkan dan menafsirkan (interpretasi) bagaimana gambaran masa lampau tersebut dan menyampaikan hasil-hasil rekontruksi tersebut secara tertulis dan kronologis yang menjadikannya sebagai sebuah kisah.

\section{HASIL DAN PEMBAHASAN}

\section{Pasca 27 Juli 1996: Bergerak Melalui}

\section{Komite-Komite Rakyat}

Pasca Peristiwa 27 Juli 1996, yaitu peristiwa penyerangan kantor DPP PDI oleh masa pendukung Soerjadi, ABRI dan preman bayaran yang meluas menjadi kerusuhan di wilayah Jakarta Pusat (Rahmat, 2013, hlm. 1). Partai Rakyat Demokratik menjadi kambing hitam dengan tuduhan sebagai dalang dari peristiwa kerusuhan tersebut. Kader partai diburu dan ditangkap, kondisi tersebut mengakibatkan tidak adanya kegiatan partai dalam beberapa bulan. Seluruh anggota partai melakukan penyelamatan diri dan menurunkan tempo aktivitas gerakan, namun dalam persembunyian tersebut anggota PRD tetap menjalin konsolidasi.

Konsolidasi dilakukan dengan upaya untuk membangun gerakan bawah tanah dibawah komando KPP-PRD yang mendapat mandat dari Ketua Umum, Budiman Sudjatmiko. KPP-PRD tersebut dipimpin oleh tiga orang, yaitu Andi Arief, Nezar Patria dan Faisol Reza (Miftahuddin, 2004, hlm. 194). KPP-PRD terdiri dari atas 15 orang, yang merupakan representasi PRD di 15 Wilayah. Pada tingkat Provinsi, PRD membentuk Komite Pengurus Wilayah (KPW), dan Komite Pengurus Kota (KPK) pada Daerah Tingkat II. Selain memberikan komando kepada KPP-PRD, konsolidasi juga memutuskan tiga langkah yang diambil organisasi, yakni (1). Membentuk tim pengacara untuk pembebasan Budiman dan kawan-kawan. (2). Penggalangan internasional dengan bekerjasama dengan jaringan Xanana Gusmao dan Ramos Horta di Lisabon, Portugal (Tempo, 2013, hlm. 42).

Menjelang 1997, konsolidasi internal mulai digelar dan menghasilkan keputusan bahwa PRD harus tetap bersama rakyat. Langkah kongkrit yang dilakukan adalah memberikan instruksi kepada setiap aktivis partai untuk mengorganisasi masyarakat dan membentuk organisasi-organisasi masyarakat sebanyak-banyaknya (Hakim, wawancara pribadi, Februari 14, 2018). Seruan tersebut merupakan 
sebuah komitmen PRD yang akan tetap melakukan konsolidasi, mobilisasi masa, dan menjalankan program-program politiknya meskipun sudah ditetapkan sebagai Organisasi Terlarang (OT).

Sesuai dengan amanat dan keputusan hasil konsolidasi partai yang dilaksanakan beberapa bulan setelah penangkapan para pimpinan partai. Pada November 1996, PRD juga sudah bisa dikelompokan lagi dan membentuk komite-komite aksi di berbagai kota yang mulai mengorganisasi aksi demonstrasi. Dalam 4 bulan sampai Mei 1997, sejumlah aksi protes terus meningkat, dan mengangkat berbagai isu (Lane, 2014, hlm. 249). Senada dengan yang disampaikan oleh Hakim (dalam wawancara pribadi, Februari 14, 2018) bahwa:

"masing-masing kader partai ditugaskan untuk mengorganisasi masyarakat di perkotaan, seperti saya yang ditempatkan di Tanah Abang dan Bendungan Hilir. Ditempat tersebut kemudian saya mengorganisasi masyarakat dan mendirikan ormas Gerakan Rakyat Pro Reformasi (GRPR), dan KOBAR (Komite Buruh untuk Aksi Reformasi)”.

Gerakan Rakyat Pro Refromasi merupakan organisasi massa yang ditujukan untuk mengorganisasi kaum rakyat miskin kota, khususnya Jabodetabek yang dipimpin oleh Iqbal. Sedangkan KOBAR merupakan organisasi massa yang menghimpun kaum pekerja industri atau buruh di wilayah Jakarta dan sekitarnya. KOBAR dipimpin oleh Lukman Hakim, seorang pengurus pusat PPBI (organisasi sektor buruh dan pekerja dari Partai Rakyat Demokratik). Secara organisasi KOBAR memiliki hubungan dengan anggota-anggota PPBI yang juga memelihara hubungan dekat dengan kelompok mahasiswa. Senada dengan Robinson \& Hadiz (2004, hlm. 183) “... many Kobar activists have links with the labour and student wings of the formerly banned PRD". Dalam beberapa aksi demonstrasi, KOBAR mengajukan tuntutan seputar buruh diantaranya adalah: kenaikan upah UMR 100\%, stop intervensi militer dan stop PHK.

Selain dua ormas tadi, di wilayah Jabodetabek juga terdapat KOMRAD (Komite Mahasiswa dan Rakyat untuk Demokrasi) yang menghimpun mahasiswa, dan KPM (Komite Pendukung Mega), merupakan ormas yang ditujukan untuk mewadahi simpatisan PDI-Mega atau oleh aktivis PRD disebut PDI-Perjuangan. Diluar Jabodetabek, pendirian komitekomite rakyat juga dilakukan. Di Solo misalnya terdapat ormas KRKB, sebuah akronim dari Komite Reformasi Kaum Buruh yang merupakan ormas yang digerakan oleh kader-kader PRD di Solo, seperti Adil, dan Widji Thukul (Hakim, wawancara pribadi, Februari 14, 2018), KRKB merupakan organisasi buruh PT. Tyfountex yang di PHK (PRD, 1999, hlm. 4).

Dalam dokumenter "Indonesian in Revolt: Democracy or Death" tergambar bagaimana KRKB melakukan aksi demonstrasi di perusahaan industri di kota Solo, tuntutan mereka adalah seputar kesejahteraan buruh, seperti kenaikan gaji dan tentunya tuntutan reformasi. Kemudian pada dua minggu selanjutnya, 800 buruh dari Solo berangkat ke Jakarta dan bergabung dengan 100 aktivis 
Jakarta menggelar long march ke Gedung Departemen Tenaga Kerja RI untuk menemui Menteri Tenaga Kerja.

Selain mendirikan komite-komite rakyat sektoral, PRD juga mendirikan KNPD (Komite Nasional Perjuangan Demokrasi) sebagai respons politik nasional. KNPD dibentuk pada 14 April 1997 sebagai organisasi legal yang berperan meningkatkan konsolidasi dan gerakan kampus. KNPD di bawah kepemimpinan Sekertaris Jendral Noor Hikmah berhasil menggalang konsolidasi persatuan mahasiswa, buruh, kaum miskin kota, dan kaum tani di berbagai kota seperti Jakarta, Yogyakarta, Semarang, Pekalongan, Solo, Surabaya, Malang, Manado, Palu, Lampung, dan Medan (Tempo, 2013, hlm. 43; Miftahuddin, 2004, hlm. 86).

Berdasarkan fakta tersebut, rupanya PRD berupaya membangun basis massa di wilayah perkotaan, terutama kota-kota besar seperti Jakarta, Tanggerang, Solo, Yogyakarta, Surabaya, dan sebagainya. Selain itu, PRD juga membangun basis masa dari beberapa sektor masyarakat, yaitu: (1) Kaum miskin kota, (2) Buruh dan pekerja industri, (3) Kaum muda dan mahasiswa, (4) Massa pendukung PDIMega.

Simpatisan PDI Mega menjadi massa yang potensial untuk mendorong demokratisasi setelah bertubi-tubi upaya penyingkiran terhadap Megawati Soekarno Putri dilakukan oleh rezim Orde Baru. Memanfaatkan momen tersebut, PRD melalui kader-kadernya mengorganisasi massa Megawati dengan membentuk Komite Pendukung Mega (KPM). KPM diresmikan pada 12 Februari 1998 di YLBHI Jakarta, dengan pimpinan dr.
Ribka Tjiptaning dan Antun Jaka Susmana dari PRD (Tempo, 2013, hlm. 45).

Solidaritas masa Megawati pada puncaknya membentuk wacana MegaBintang-Rakyat yang mencuat pada musim kampanye 1997 sebagai pembentukan opini sentiment anti rezim Orde Baru oleh PRD. PRD bahkan memproduksi selebaran Mega-Bintang-Rakyat sejumlah sekitar 500 ribu eksemplaryang ditambahi wacana "Gulingkan Soekarno", dan "Bentuk Pemerintah Sementara" (Miftahuddin, 2004, hlm. 195). Selebaran Mega-BintangRakyat bertujuan untuk membangun front yang lebih luas antara koalisi massa Partai Demokrasi Indonesia Megawati dan Partai Persatuan Pembangunan. Meskipun terdapat larangan membawa poster dan perlengkapan Mega-BintangRakyat dengan alasan "tidak ada partai yang terdaftar atas nama Mega-BintangRakyat" (Lane, 2014, hlm. 259), namun tuntutan-tuntutan massa rakyat semakin meluas.

PRD terus mengembangkan strategi politisnya, setidaknya terdapat beberapa tuntutan PRD menjelang Pemilu 1997: (1) menolak campur tangan pemerintah dalam urusan internal PDI ; (2) mendukung Megawati sebagai pemimpin alternatif dan mencalonkan Megawati sebagai Presiden; (3) Menuntut dicabutnya UU Kepartaian 1985 dan Dwi Fungsi ABRI ; (4) Menuntut perlunya partai politik baru dan Presiden baru (Priyono, 2001, hlm. 212). Dilihat dari tuntutan tersebut, menjelang Pemilu 1997 PRD terus menyuarakan tuntutantuntutan strategis yang mendesak dan dekat dengan momentum pemilu. Meskipun begitu, PRD juga tetap menuntut pencabutan atas paket atas lima Undang- 
Undang Politik, pencabutan Undang Undang Subversif PNPS No.11 Tahun 1963, referendum Timor-Timur, meminta pengadilan Internasional mengadili pemerintah atas kejahatan kemanusiaan pada 1965 (Argenti, 2016, hlm. 129). Meskipun hal tersebut tidak mendesak bagi rakyat, namun sangat strategis untuk memberikan pemahaman masyarakat untuk memperjuangkannya.

Menjelang Pemilu 1997, PRD juga mengkampanyekan untuk memboikot pemilu. Bahkan koordinator KPPPRD, Mirah Mahardika yang kemudian diketahui sebagai nama samaran Andi Arief (PRD, 1997, hlm. 5) menyarankan agar PDI Mega harus memboikot Pemilu 1997. Menurutnya memboikot adalah sikap yang paling tepat. Menurutnya boikot adalah sikap oposisi aktif, tidak pasrah. Kampanye PRD memboikot Pemilu 1997 didasarkan pada anggapan bahwa Pemilu 1997 berpontensi menjadi pemilu paling buruk, curang, dan kasar dan tak konstitusional.

Pada 30-31 Agustus 1997, Partai Rakyat Demokratik mengadakan pertemuan Dewan Nasional di Jakarta, di Hotel Central, yang dihadiri peserta dari berbagai daerah. Pada pertemuaan tersebut menghasilkan keputusan untuk membentuk struktur-struktur perlawanan di basis-basis masyarakat kemudian direspons dengan pemetaan wilayah. Hasilnya adalah di Jakarta terdapat 150 kelurahan, setidaknya dibutuhkan 150 anggota partai untuk memobilisasi masa ditiap kelurahan. Untuk itu sebelum SU MPR 1998 digelar, diputuskan bahwa seluruh kader diluar Jakarta ditarik ke Jakarta (Miftahuddin, 2004, hlm. 195).
Kader-kader dari luar Jakarta tersebut kemudian ditempatkan di setiap kelurahan di Jakarta, mereka dituntut untuk bisa bersosialisasi dengan warga sekitar karena pada umumnya para kader luar kota tersebut tidak memiliki sanak saudara atau kerabat di wilayah dimana mereka ditugaskan.

Strategi PRD menjelang SU MPR 1998 tersebut terbilang berhasil, berdasarkan laporan Yayasan Insan Politika (dalam Lane, 2014, hlm. 267) bahwa terdapat paling tidak 30 sampai 40 demonstrasi di seluruh negeri setiap harinya selama periode Maret-Mei. Puluhan ribu rakyat dari seluruh sektor masyarakat terlibat demonstrasi, khususnya kaum miskin kota, termasuk buruh pabrik, buruh kerah putih, guru, dokter.

Menjelang SU MPR tahun 1998, masyarakat dihebohkan dengan terjadinya ledakan bom di kawasan rumah susun (Rusun) Tanah Tinggi Jakarta Pusat pada minggu sore 18 Januari 1998. Peristiwa tersebut terjadi pada pukul 18.30 di Rusun Blok V lantai V RT.10 RW.04 No.510 (ABRI, 1998, hlm.1). Dalam peristiwa tersebut kemudian ditangkap Agus Priyono, salah seorang anggota Partai Rakyat Demokratik dan Komite Nasional Pemuda untuk Demokrasi (KNPD). Selain itu, beberapa hal yang mengkaitkan ini dengan PRD adalah dengan ditemukannya paspor milik Daniel Indrakusumah, salah seorang anggota PRD, sejumlah surat dari tokoh SMID yang ditujukan untuk Sekjen PRD, Petrus Haryanto dan ditemukan juga sejumlah dokumen, buku-buku dan berkas-berkas yang berkaitan erat dengan aktivitas PRD selama ini (Berita Yudha, 1998, hlm. 4). 
Setelah peristiwa bom tanah tinggi, pimpinan PRD bawah tanah dan beberapa aktivis PRD ditangkap dan diculik, beberapa diantaranya adalah Nezar Patria, Faisol Reza, Andi Arief, Widji Thukul, Bimo Petrus. Berdasarkan laporan dari Komisi untuk Orang Hilang dan Korban Tindak Kekerasan (Kontras) menyebutkan bahwa sepanjang 1997-1998 terdapat 23 orang yang diculik, dimana satu orang sudah ditemukan tewas, sembilan orang dibebaskan dan tiga belas orang lainnya masih hilang (Kontras, 2009).

Penculikan 23 orang aktivis prodemokrasi tersebut tidak menurunkan intensitas gerakan pada saat itu, karena struktur-struktur gerakan sudah dibangun dalam basis massa perkampungan. Semakin hari gerakan pro-demokrasi yang melibatkan seluruh elemen masyarakat semakin meluas dan membesar secara intensif dan ekstensif. Hingga puncaknya terjadi pada bulan Mei, ketika aksi damai mahasiswa Universitas Trisakti berujung pada tembak mati kepada empat orang mahasiswa oleh aparat keamanan. Hal ini semakin membuat massa aksi semakin tidak terkendali, demonstrasi disertai dengan kerusuhan meluas terjadi dimana-mana (Kasenda, 2015, hlm. 144). Hingga akhirnya masyarakat beserta mahasiswa melakukan long march di jalur Revolusi (Senen-Kramat-Salemba) hingga ke Gedung DPR-MPR, dan terjadi pendudukan gedung DPR/MPR oleh mahasiswa. Hingga pada akhirnya, pada 21 Mei 1998 Soeharto mengumumkan mengundurkan diri dari jabatannya sebagai Presiden Republik Indonesia sekaligus mengakhiri 32 tahun masa kekuasaannya.

\section{Strategi Pemenangan Partai Rakyat Demokratik dalam Pemilu 1999}

Pasca mundurnya Soeharto pada 21 Mei 1998, iklim demokratis makin meluas. Hal tersebut membawa angin segar terhadap Partai Rakyat Demokratik. PRD yang sebelumnya merupakan organisasi terlarang dinyatakan sebagai organisasi yang resmi oleh pemerintah. Keputusan tersebut didapat atas dasar gugatan yang telah diajukan pada september 1997 dengan melalui Pengadilan Tata Usaha Negara (PTUN). Namun, baru pada bulan September 1998 PTUN memenangkan gugatan PRD terhadap Mendagri, sehingga SK tentang pelarangan PRD dinyatakan batal demi hukum (Miftahuddin, 2004, hlm. 151).

Setelah PTUN memenangkan gugatan PRD terhadap SK Mendagri mengenai PRD sebagai organisasi terlarang pada bulan September 1998. Kemudian, pimpinan PRD dari dalam penjara memberikan mandat kepada Hendri Kuok untuk memimpin Kepal-PRD (Komite Persiapan Legalisasi Partai Rakyat Demokratik) dengan tujuan untuk memperjuangkan pembebasan tapol PRD, dan seluruh tapol lainnya, dan pencabutan SK pelarangan PRD.

PRD kemudian menggelar Kongres II di Yogyakarta, yang memutuskan pembentukan Komite Pimpinan Pusat PRD (KPP-PRD). Dalam Kongres tersebut juga memperdebatkan mengenai peran politik yang harus diambil oleh PRD menghadapi Pemilu. Perdebatan tersebut kembali muncul dibicarakan dalam pertemuan Dewan Nasional Partai. Tanggal 13-15 Februari 1999 berlangsung Rapat Kerja Nasional PRD di Jakarta yang dihadiri 
utusan 12 Komite Pimpinan Wilayah. Rakernas memutuskan bahwa PRD akan berpartisipasi dalam Pemilu pada bulan Juni 1999 (Miftahuddin, 20014, hlm. 195). Kesempatan turut serta dalam pemilu adalah taktik sekaligus alat untuk menyuburkan perkembangan kuncupkuncup kesatuan rakyat-mahasiswa. Dengan alat Pemilu, PRD akan lebih mudah berbicara pada rakyat dan mahasiswa.

Berikut ini adalah beberapa dasar pertimbangan bagi PRD untuk memutuskan untuk ikut Pemilihan Umum 1999 yang dikutip dari artikel berjudul “Mengapa PRD Ikut Pemilu?” yang dimuat dalam kolom Arena Kampanye harian Pikiran Rakyat (1999b) :

1. PRD sangat memahami keinginan masyarakat yang antusias terhadap pemilu, sehingga PRD harus menyesuaikan taktik perjuangannya. PRDharusjuga memanfaatkan alat-alat pemilu untuk memberikan pendidikan politik pada rakyat, mengingatkan rakyat tentang memperjuangkan program-program reformasi total.

2. PRD sama sekali tidak menaifkan kemungkinan untuk menolak pemilu yang tidak jurdil. Tugas PRD ketika turut serta dalam pemilu adalah mengingatkan rakyat agar mereka sadar bahwa pemilu yang akan diselenggarakan tidak jurdil dan memberi penjelasan syarat-syarat pemilu yang jurdil sekaligus. Jika rakyat menolak pemilu, maka PRD dan rakyat akan membangun kekuatan. Tapi bila masyarakat kemudian tetap ingin memilih jalan pemilu, maka pilihlah, cobloslah PRD, untuk membuka harapan jalan baru, jalan tambahan, selain perjuangan massa di jalan-jalan.

3. PRD bahkan sampai sekarang adalah partai yang ditindas oleh cara-cara kediktatoran militeristik sehingga tidak memiliki kesempatan mengumpulkan dukungan dana dan logistik yang melimpah. Untuk mengatasi kekurangan tersebut, PRD ikut serta dalam pemilu agar mempunyai ruang dan kesempatan lebih luas dalam memberikan pendidikan politik pada rakyat serta mempropagandakan program-program tuntutan PRD.

4. Perjuangan parlementaris PRD harus dapat menunjukan pada rakyat bahwa pemilu dan parlemen yang dihasilkan undang-undang pemilu yang tidak demokratis, tidak jurdil, dan diikuti partai-partai yang suka menipu rakyat serta mengkompromikan programprogramnya akan menghasilkan parlemen yang lumpuh, tidak mempunyai kedaulatan serta tak lebih dari sekumpulan pencari karier politik yang hanya sibuk mencari kompromi dan konsensi-konsensi untuk kepentingan kelompok dan partainya. PRD akan membongkar bukti-bukti kejahatan tersebut pada pemilu 1999 ini, atau para wakil PRD yang terpilih di dalam parlemen nanti berapa pun jumlahnya.

5. Keikutsertaan PRD dalam pemilu/ pemerintahan tidak meniadakan taktik perjuangan garis massa yang menjadi metode perjuangan PRD selama ini. Perjuangan parlementaris, hanyalah corong atau juru bicara untuk mengabarkan tuntutantuntutan gerakan massa kepada 
rakyat mengkombinasikan kedua arena perjuangan demokrasi ini akan memberikan tekanan lebih besar pada warisan politik rezim Orde Baru. (hlm. 10)

Pada tanggal 22 Februari, PRD mendaftarkan diri ke Departemen Kehakiman untuk mengikuti Pemilu, dan kemudian dinyatakan lulus persyaratan administratif dan mendapat pengakuan legal melalui SK Menteri Kehakiman Nomor 129/A/PP-PARPOL/II/1999 (Cahyo, 2016, hlm. 108). Pada 24 Februari 1999, PRD mendaftarkan diri ke LPU untuk diverifikasi oleh tim-11. Dalam pendaftaran tersebut PRD menyerahkan daftar 12 Komite Pimpinan Wilayah (KPWPRD). Dan pada tanggal 4 Maret tim-11 mengumumkan PRD lolos verifikasi dan berhak mengikuti Pemilu 1999. Setelah itu, PRD kemudian mengirimkan delegasinya, yaitu Hendri Kuok sebagai wakil PRD dalam Komisi Pemilihan Umum (KPU). (Miftahuddin, 2004, hlm. 153).

Dalam beberapa persiapan menjelang Pemilu, PRD menyatakan sikap bahwa tidak akan mengakui Pemilu yang dilaksanakan di provinsi termuda, TimorTimur dan mengkampanyekan referendum (ABRI, 1999, hlm. 1). PRD menyerukan bahwa yang dibutuhkan rakyat TimorTimur adalah referendum untuk menentukan nasib sendiri karena daerah tersebut tidak bertuan menurut hukum internasional. Memang, sejak awal PRD didirikan mereka telah menyatakan sikap untuk memperjuangkan kemerdekaan Timor Timur.

Sikap PRD yang menolak diadakannya Pemilu di Timor-Timur terjadi saat dilaksanakan Peresmian Panitian
Pemilihan Daerah (PPD) I di Timtim 29 Maret 1999, wakil PRD di PPI, yaitu Aan Rusdianto menolakuntukmenandatangani berita acara peresmian PPD I tersebut (Kompas, 1999, hlm. 8). Aan Rusdianto justru menandatangani surat yang isinya antara lain menolak tiga UndangUndang (UU) Politik 1999. Sikap Partai Rakyat Demokratik di acara peresmian PPD I tersebut kemudian dibahas dalam rapat pleno Panitia Pemilihan Indonesia (PPI) pada Senin, 5 April 1999. Dalam rapat tersebut seluruh anggota PPI mengecam tindakan yang dilakukan PRD dan mengusulkan agar Aan Rusdianto diberikan sanksi (Kompas, 1999, hlm. 8).

Kendati sikap PRD dalam Komisi Pemilihan Umum dan Panitia Pemilihan Indonesia dianggap merugikan kepentingan nasional dan menuai banyak kecaman, namun PRDbersikerastidakakan menarik diri dari Pemilu 1999. PRD tetap akan mempertahankan keberadaannya di KPU, dan justru Faisol Reza selaku Ketua KPP-PRD menyampaikan bahwa PRD akan melakukan propaganda di KPU (Kompas, 1999, hlm. 8).

Bersamaan dengan dinamika yang dihadirkan PRD di KPU. Dibalik jeruji besi LP Cipinang para aktivis PRD melakukan aksi mogok makan dalam rangka menuntut agar pelaksanaan pemilu yang jujur dan adil. Aksi mogok makan ini dimulai pada tanggal 6 April 1999 dan berlangsung kurang lebih satu minggu hingga 12 April 1999 (Republika, 1999, hlm. 4). Aksi mogok makan aktivis PRD di LP Cipinang tersebut dilakukan sebagai upaya menyadarkan semua pihak bahwa Pemilu harus diselenggarakan secara jujur dan adil. 
PRD juga menyampaikan beberapa persyaratan agar pemilu berlangsung secara jujur dan adil. Beberapa persyaratan tersebut adalah: (1). Dihapuskannya Dwifungsi ABRI, dalam artian tak ada lagi peran sosial politik ABRI, dengan konsekuensi tidak perlu ada fraksi ABRI di DPR, sehingga ABRI hanya berfungsi sebagai alat pertahanan; (2). Partai politik diberikan kebebasan dan keleluasaan untuk memiliki asas ideologi dan garis politiknya serta bebas mengkampanyekannya; (3) Syarat yang terakhir, tidak adanya politik uang (money politics) dalam meraih dukungan masyarakat dan memenangkan pemilihan umum (Kompas, 1999, hlm. 4).

Menghadapi Pemilu 1999, Partai Rakyat Demokratik tidak khawatir perihal perolehan suara dalam pemilihan kali ini. Faisol Reza selaku Ketua Komite Pimpinan Pusat PRD menyampaikan bahwa target PRD dalam pemilu kali ini hanya dua persen lebih (Media Indonesia, 1999, hlm. 2). Meskipun demikian, PRD cukup optimis dapat meraih suara dalam kancah Pemilu ini, terdapat 12 wilayah yang menjadi perhatian PRD, dan PRD juga mempunyai basis pendukung massa yang cukup banyak. Dua belas wilayah tersebut adalah Sumatera Utara, Sumatera Selatan, Lampung, DKI Jakarta, Jawa Barat, Jawa Tengah, DI Yogyakarta, Jawa Timur, Kalimantan Barat, Sulawesi Selatan, Sulawesi Tengah, Sulawesi Utara. Selain wilayah basis tersebut, PRD juga menempatkan sektor mahasiswa, kaum muda, dan pekerja industri modern sebagai basis masa pemilihnya. Selain tiga sektor tersebut, masa marjinal yang selama ini menjadi titik orientasi PRD, dilebarkan ke kaum gay dan lesbian (Chist, 1999, hlm. 7).
Dalam Pemilu 1999, PRD hanya mendaftarkan 26 kader terbaiknya dalam pemilihan calon legislatif, diantaranya adalah Ketua Umum mereka, yaitu Budiman Sudjatmiko dan Ketua PPBI Dita Indah Sari yang keduanya berstatus sebagai tahanan di LP Cipinang dan LP Wanita Tanggerang. Selain mendaftarkan kader yang berstatus sebagai tahanan, PRD juga mendaftarkan kader-kader yang menjadi korban penculikan dan telah meninggal. Seperti, Petrus Bimo dan Herman Hermawan, Suyat dan Gilang. Hakim (dalam wawancara pribadi, Februari 14, 2018) menyampaikan bahwa alasan PRD mendaftarkan kader-kader mereka yang berstatus sebagai tahanan, korban penculikan bahkan yang telah meninggal adalah hal simbolik. PRD ingin mengingatkan kepada masyarakat Indonesia bahwa perjuangan Reformasi meruntuhkan rezim Orde Baru harus dibayar dengan pengorbanan, baik itu menjadi tahanan, hilang diculik bahkan hingga meninggal.

Strategi kampanye yang dilakukan PRD pun relatif berbeda dengan partai-partai politik lainnya. PRD tidak mengobral umbul-umbul dan bendera partai di setiap sisi kota, namun PRD menyebarkan lebih banyak berupa selebaran mengenai program partai. Memang, pada awalnya PRD memutuskan untuk ikut Pemilu adalah karena PRD ingin melakukan pendidikan politik terhadap masyarakat. Kampanye terbuka pun tidak luput dari strategi yang dilakukan oleh PRD. Pada 23 Mei 1999, PRD mengadakan kampanye di depan LP Cipinang. Kampanye yang sekaligus demonstrasi tersebut dihadiri oleh ratusan kader dan pendukung Partai Rakyat Demokratik. Dalam kesempatan 
itu PRD menuntut pembebasan terhadap seluruh Napol dan Tapol tanpa terkecuali, termasuk Ketua Umum dan rekanrekan PRD yang masih ditahan. Selain itu, PRD juga menuntut pemerintahan Habibie untuk mengadili mantan Presiden Soeharto, dan menyerukan bahwa rakyat harus membentuk pemerintahan transisi.

Setelah melakukan orasi di depan LP Cipinang, kemudian massa PRD melanjutkan dengan konvoi dan menyebarkan selebaran program partai di jalan raya. Dalam Pemilihan Umum 1999, KPU juga mempersiapkan arena bagi setiap partai untuk mempromosikan program-program politik masing-masing dengan menggunakan media-media massa Nasional, seperti televisi dan radio. Hal ini tentunya dimanfaatkan oleh Partai Rakyat Demokatik untuk mengkampanyekan program politik mereka.

Selain menyelenggarakan kampanye terbuka, dalam rangka upaya meraih suara dari pemilih kaum muda, dan pemula yang menjadi salah satu bidikan PRD dalam Pemilu 1999, PRD juga menyelenggarakan sebuah acara musik underground di Bengkel Café Jakarta (Chist, 1999, hlm. 7). Tentunya penyelenggaraan acara musik tersebut merupakan bentuk terobosan baru PRD dalam meraih dukungan dalam kalangan anak muda, khususnya pencinta musik underground.

Setelah dilaksanakan pemungutan suara, pada tahap penghitungan suara dan pembagian kursi PRD menolak menandatangani berita acara perhitungan suara dengan alasan Pemilu yang diadakan belum jurdil (jujur adil). Pada dasarnya pelaksanaan pemilihan umum 1999 belum benar-benar demokratis karena peranan pemerintah masih dominan dan UU Politik memberikan jatah 38 kursi di DPR bagi ABRI (Herin, 1999).

PRD sendiri dalam pemilihan umum 1999 memperoleh 78.730 suara pada tingkat Nasional (Miftahuddin, 2004). Jumlah tersebut hanya terhitung $0,07 \%$, sementara ambang batas suara atau electoral threshold adalah 2\%, sehingga PRD tidak berhasil memperoleh satupun kursi di legislatif pusat. Kendati pada tingkat daerah satu orang calon legislatif dari PRD mendapatkan satu kursi di DPRD. Namun, menurut Hakim (dalam wawancara pribadi, 14 Februari 2018) bahwa meskipun terdapat beberapa kader yang lolos ke legislatif, namun pada akhirnya kesempatan itu tidak diambil, PRD memilih mengundurkan diri dari pencalonan. Pada dasarnya PRD mengikuti pemilu bukan untuk kekuasaan politik semata, namun ingin mengkampanyekan program-program dan tuntutan reformasi total dengan menggunakan pemilu sebagai sarana politiknya.

Lane (2014, hlm. 452-453) menyimpulkan beberapa faktor yang melatarbelakangi kegagalan PRD dalam Pemilu 1999, yaitu: (1) Terdapat perbedaan pendapat terkait pilihan taktik apakah harus intervensi terhadap pemilu atau tidak, (2) Sebagai partai yang berbasis gerakan, dana yang dimiliki PRD sangat minim untuk melakukan kampanye terbuka, (3) framing dan stigma bahwa PRD adalah reinkarnasi PKI sangat kuat dan diperkuat oleh trauma politik rakyat terhadap kelompok berhaluan kiri dan sosialis, (4) terlalu pendeknya waktu yang dimiliki PRD untuk menyiapkan organisasi untuk melakukan kampanye 
elektoral. Setelah momentum Pemilu 1999 usai, PRD tetap hadir dan berusahan mengkonsolidasi kekuatan oposisi dengan menegaskan beberapa permasalahan, diantaranya adalah reformasi yang belum menghasilkan transformasi total.

\section{Simpulan}

Dalam perjuangan menyuarakan program-program politiknya, PRD selalu berhadapan dengan represifitas pemerintah, misalnya pada peristiwa 27 Juli 1996 yang berakhir pada penangkapan kader dan pembubaran partai. Namun, senada dengan teori pegas bahwa semakin ditekan maka semakin kuat daya pegas suatu benda. Maka, aksi-aksi represif rezim OrdeBarutersebutpuntidakmenghentikan gerakan perlawanan terhadap rezim Orde Baru, justru melahirkan perlawanan yang lebih besar dan luas.

PRD kemudian membangun struktur perlawanan dalam empat sektor di wilayah perkotaan, yaitu kaum miskin kota, buruh, mahasiswa dan pendukung Megawati. Hal ini dapat dipahami mengingat pada periode tersebut struktur perlawanan dipersiapkan untuk melakukan aksi kolektif dalam momen Pemilu 1997, dan Sidang Umum MPR 1998. Dalam hal ini, PRD berhasil membangun sentimen terhadap rezim Orde Baru dan menciptakan kesadaran di masyarakat mengenai bobroknya pemerintahan Soeharto. Puncaknya adalah peristiwa Reformasi 1998 sebagai mosi tidak percaya masyarakat kepada pemerintahan Soeharto.
Keikutsertaan PRD dalam pemilu tidak bisa dimaknai secara tunggal bahwa PRD menginginkan suara dan menempatkan kader mereka dalam parlemen. Karena, PRD sendiri mengklaim bahwa tujuan utama mereka adalah memberikan pendidikan politik kepada masyarakat untuk memperjuangan reformasi total. Langkah PRD tersebut dapat ditafsirkan bahwa PRD tidak mau kehilangan momen pemilu sebagai wahana kampanye politik, namun juga tidak kehilangan idealisme partai yang sejak dulu menyuarakan pelaksanaan pemilu yang jujur dan adil. Sifat dualisme PRD tercermin dalam wacana "Coblos PRD atau Boikot Pemilu!".

Kegagalan PRD dalam Pemilu 1999 adalah jelas karena partai ini didesain sebagai partai ideologis dan partai massa, bukan sebagai partai elektoral yang didesain dapat meraup suara dalam pemilu. Sebagai partai ideologis yang mengusung Sosial Demokrasi Kerakyatan sebagai asasnya, PRD terjebak dalam ceruk pemilih yang terbatas. Meskipun, PRD tidak menerapkan inklusifitas dalam segmen politiknya, dan cenderung lebih terbuka terhadap berbagai segmen pemilihnya. Namun, pada realitanya ceruk pemilih PRD datang dari masyarakat yang memiliki pandangan-pandangan revolusioner dan jumlahnya pun terbatas. 
CAHYO SUSILO

DARI AKSI HINGGA PESTA DEMOKRASI: DINAMIKA PARTAI RAKYAT DEMOKRATIK MENUJU

PEMILU (1996-1999)

\section{DAFTAR PUSTAKA}

Hamid, Abd.R \& Madjid, M.S. (2011b). Pengantar Ilmu Sejarah. Yogyakarta: Penerbit Ombak.

Ismaun. (2005). Sejarah Sebagai Ilmu. Bandung: Historia Utama Press.

Kasenda, P. (2015). Hari-Hari Terakhir Orde Baru. Depok: Komunitas Bambu.

Lane, M. (2014). Unfinished Nation: Ingatan Revolusi Aksi Massa dalam Sejarah Indonesia. Jakarta: Djaman Baroe.

Miftahuddin. (2004). Radikalisasi Pemuda : PRD Melawan Tirani. Jakarta: Penerbit Desantara.

Priyono, A.E. (Penyunting). (2001). Aktor Demokrasi: Catatan Tentang Gerakan Perlawanan di Indonesia. Institut Studi Arus Informasi (ISAI): Jakarta.

Robinson, R \& Hadiz, V.R. (2004). Reorganising Power in Indonesia: The Politicts of Oligarchy in Age of Market. London: Routledge Curzon.

Sjamsudin, H. (2012). Metodologi Sejarah. Yogyakarta: Penerbit Ombak.

Tempo. (2013). Seri Buku Tempo Wiji Thukul: Teka-teki Orang Hilang. Jakarta: Penerbit KPG.

\section{Artikel dalam Jurnal \& Skripsi}

Argenti, G. (2016). Transformasi Gerakan Sosial Ke Partai Politik Kiprah Politik Partai Rakyat Demokratik Di Masa Reformasi. Jurnal Wacana Politik. Vol.1 (2). Hlm. 122-136.

Rahmat, A,A. (2013). Peristiwa 27 Juli 1996 (Konflik dalam Partai Demokrasi Indonesia Antara Kubu Megawati dengan Kubu Soerjadi). Factum: Jurnal Sejarah dan Pendidikan Sejarah. Vol.2 No.2. Hlm.1.
Cahyo, M. S.S.S.D. (2016). Ideologi Sosialisme Indonesia Prespektif Partai Rakyat Demokratik : Komite Pimpinan Wilayah PRD Lampung Tahun 20102015. Skripsi. Fakultas Ilmu Sosial dan Ilmu Politik, Universitas Lampung, Bandar Lampung.

\section{Surat Kabar dan Artikel Internet}

ABRI. (1998, 20 Januari). "Polisi Buru Perancang Bom Di Tanah Tinggi”. ABRI, hlm. 1.

Berita Yudha. (1998, 21 Januari). "Bom Rakitan Tidak Mungkin Hancurkan Gedung”. Berita Yudha, hlm. 4.

Chist. (1999, 21-27 April). "Massa PRD Menyongsong Pemilu”. Tabloid Adil. Hlm.6-7.

Herin, S. (1999, Februari-Maret). "Kekuatan Pro-Demokrasi Harus Bersatu”. Majalah Siaga Edisi 4 Tahun 1.

Kompas. (1999, 8 April). "Napol PRD Tuntut Pemilu Jurdil dengan Mogok Makan”. Kompas, hlm. 4.

Kompas. (1999, 8 April). “Akibat Menolak Pemilu di Timtim, Mendagri Protes $P R D$ ”. Kompas, hlm. 8.

Media Indonesia. (1999, 20 Mei). "Banyak Partai Kekurangan Dana”. Media Indonesia, hlm. 2.

Pikiran Rakyat. (1999b, 28 Mei). "Mengapa PRD Ikut Pemilu?”. Pikiran Rakyat, hlm. 10.

Republika. (1999,13 April ). "Gara-gara Aksi Mogok Makan, Sejumlah Aktivis PRD Terpaksa Dilarikan ke RS Polri”. Republika, hlm. 4.

Kontras. (2009). Kasus Penculikan dan Penghilangan Paksa, Riwayatmu Kini?. [Online]. Diakses dari https:// www.KontraS.org/data/kertas\%20 
FACTUM

Volume 8, No.1 April 2019

posisi\%20singkat\%20Penculikan\%20

1998-2009.pdf

\section{Wawancara Perseorangan}

Hakim, Lukman. Wawancara Pribadi. 14 Februari 2018. 